\section{(6) OPEN ACCESS}

\title{
Tuberculosis and other opportunistic infections in tofacitinib-treated patients with rheumatoid arthritis
}

\author{
K L Winthrop, ${ }^{1}$ S-H Park, ${ }^{2}$ A Gul, ${ }^{3}$ M H Cardiel, ${ }^{4}$ J J Gomez-Reino, ${ }^{5}$ Y Tanaka, ${ }^{6}$ \\ K Kwok, ${ }^{7}$ T Lukic, $^{7}$ E Mortensen, ${ }^{8}$ D Ponce de Leon, ${ }^{9}$ R Riese, $^{10}{ }^{10}$ Valdez $^{7}$
}

\begin{abstract}
Handling editor Tore K Kvien
- Additional material is

published online only. To view please visit the journal online (http://dx.doi.org/10.1136/ annrheumdis-2015-207319)
\end{abstract}

For numbered affiliations see end of article.

\section{Correspondence to} Dr Kevin L Winthrop, CEI/ OHSU, 3375 SW Terwilliger Blvd, Portland, OR 97239, USA; Winthrop@ohsu.edu

Received 16 January 2015 Revised 2 July 2015 Accepted 5 July 2015 Published Online First 28 August 2015

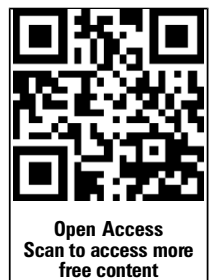

\section{ABSTRACT}

Objectives To evaluate the risk of opportunistic infections (Ols) in patients with rheumatoid arthritis (RA) treated with tofacitinib.

Methods Phase II, III and long-term extension clinical trial data (April 2013 data-cut) from the tofacitinib RA programme were reviewed. Ols defined a priori included mycobacterial and fungal infections, multidermatomal herpes zoster and other viral infections associated with immunosuppression. For Ols, we calculated crude incidence rates (IRs; per 100 patient-years $(95 \% \mathrm{CI})$ ); for tuberculosis (TB) specifically, we calculated rates stratified by patient enrolment region according to background TB IR (per 100 patient-years): low $(\leq 0.01)$, medium $(>0.01$ to $\leq 0.05)$ and high $(>0.05)$.

Results We identified 60 Ols among 5671 subjects; all occurred among tofacitinib-treated patients. TB (crude IR $0.21,95 \% \mathrm{Cl}$ of (0.14 to 0.30$)$ ) was the most common OI $(n=26)$; median time between drug start and diagnosis was 64 weeks (range 15-161 weeks). Twenty-one cases (81\%) occurred in countries with high background TB IR, and the rate varied with regional background TB IR: low 0.02 (0.003 to 0.15), medium 0.08 (0.03 to 0.21$)$ and high 0.75 (0.49 to 1.15). In Phase III studies, 263 patients diagnosed with latent TB infection were treated with isoniazid and tofacitinib concurrently; none developed TB. For Ols other than TB, 34 events were reported (crude IR 0.25 (95\% CI 0.18 to 0.36$)$ ).

Conclusions Within the global tofacitinib RA development programme, TB was the most common Ol reported but was rare in regions of low and medium TB incidence. Patients who screen positive for latent TB can be treated with isoniazid during tofacitinib therapy.

\section{INTRODUCTION}

Tuberculosis (TB) and other opportunistic infections (OIs) occur more frequently in patients with rheumatoid arthritis (RA), and this risk is elevated by the use of prednisone and certain biological disease-modifying antirheumatic drugs (DMARDs). ${ }^{1-3}$ This has been best documented for granuloma-inducing pathogens in the setting of tumour necrosis factor-alpha (TNF) blockade. ${ }^{4-9}$ For biological therapies with other mechanisms of action, and for small molecular therapies like tofacitinib, less is known. Tofacitinib is a smallmolecule oral Janus kinase (JAK) inhibitor approved for the treatment of adult patients with RA. ${ }^{10}$ Tofacitinib preferentially inhibits JAK3 and JAK1, modulating the immune response via downregulation of several cytokines (eg, interleukins (ILs) 2, 4, 7, 9, 15 and 21) that are integral to lymphocyte development and function. ${ }^{11}$ Given its mechanism of action, the risk of TB and other OIs could potentially be elevated in tofacitinib-treated patients, and accordingly, we undertook a retrospective evaluation of all OIs reported within the tofacitinib RA clinical development programme.

\section{METHODS}

\section{Development programme conduct}

Following completion of phase I studies, the global tofacitinib RA development programme comprised six phase II, ${ }^{12-17}$ six phase III $^{18-23}$ and two openlabel long-term extension (LTE) studies, ${ }^{24} 25$ with a total of 5671 treated patients and 12664 patientyears tofacitinib exposure across 48 nations worldwide.

\section{OI case-finding and case description}

For phase II, III and open-label LTE studies, we searched all preferred and low-level MedDRA terms (see online supplementary file 1) reported by site investigators containing text consistent with a potential OI using a data cut-off date of 10 April 2013. As of April 2013, data collection for one phase III study ${ }^{23}$ and the two LTE studies ${ }^{24} 25$ were ongoing, and study databases had not yet been locked. For this analysis, the following infections were defined a priori as OIs: TB, non-tuberculous mycobacterium (NTM) infections, all fungal infections (with the exception of oral or vaginal candidiasis and chromomycosis), listeria and viral infections typically associated with immunosuppression, including multidermatomal or disseminated herpes zoster, disseminated herpes virus, cytomegalovirus (CMV), BK virus and progressive multifocal leukoencephalopathy (PML). Legionella was not specified as an OI and was not included in this analysis (one case was reported during the development programme).

For cases classified as 'OIs', we reviewed adverse reaction report forms to obtain clinical details, including treatment and outcomes. For all cases, we collected descriptive clinical and epidemiological information at time of randomisation (baseline) including age, sex, race, site of enrolment, corticosteroid use (limited by protocol to $\leq 10 \mathrm{mg} /$ day prednisone equivalent), concomitant non-biological DMARD use, comorbidities (eg, smoking, diabetes, others), body mass index, measures of RA severity (Disease Activity Score using 28-joint counts and the $\mathrm{C}$ reactive protein level (DAS 28-3 CRP)) and disease duration (years since diagnosis), as well as baseline lymphocyte and neutrophil counts. 


\section{TB screening}

In phase II studies, patients with positive TB screening were excluded from entering the trial. In phase III studies, all potential study subjects were queried regarding a history of prior diagnosis or treatment of active or latent TB infection (LTBI). All patients underwent chest radiography (within 3 months of screening), and for those with no prior history of positive screening results, at least one screening test for LTBI was performed at discretion of the site primary investigator; QuantiFERON-TB Gold In-Tube (QFT-IT; Quest Diagnostics, Madison, New Jersey, USA) or tuberculin skin test (TST; using $\geq 5 \mathrm{~mm}$ induration cut-off outside Japan and $\geq 20 \mathrm{~mm}$ erythema for Japan). Patients diagnosed with LTBI and patients with a history of inadequately or untreated LTBI prior to screening were allowed entry into phase III trials after receiving at least 1 month of a planned 9-month isoniazid preventive therapy regimen.

\section{OI incidence rate calculations and evaluation of comparative risk}

OIs were attributed either to tofacitinib, placebo, adalimumab or methotrexate based on exposure at time of event. Given all OIs occurred in tofacitinib patients, we calculated OI crude incidence rates (IRs) per 100 patient-years (95\% CI) only for tofacitinib-exposed patients. Given that no OIs occurred in phase II studies, these calculations were limited to the phase III and LTE studies. Patients were censored at time of event, death or withdrawal from study.

\section{TB substudy}

For TB cases, we obtained detailed information regarding date of onset, type of presentation and clinical outcomes. We also evaluated TB screening results among patients who entered the phase II, III and LTE studies. In addition, for patients who started isoniazid preventive therapy and entered trials, we described the proportion of individuals who developed elevated transaminases. We calculated crude TB IRs overall, as well as stratified by enrolment region, age, sex and baseline corticosteroid use. In order to contextualise the regional variation in TB rates, we presented $\mathrm{TB}$ rates according to regional background TB incidence. We used WHO TB incidence data from 2011, ${ }^{26}$ to categorise countries where enrolment took place according to background TB IR (per 100 patient-years) defined as follows: low-incidence regions (IR $\leq 0.01$ per 100 patient-years), medium-incidence regions (IR $>0.01$ to $\leq 0.05$ per 100 patientyears) and high-incidence regions (IR $>0.05$ per 100 patientyears). We conducted all statistical analyses using SAS software (SAS Institute, Cary, North Carolina, USA).

\section{RESULTS}

Patient baseline characteristics are described in table 1 . We identified 60 OIs (58 patients) among 5671 patients enrolled in phase II, phase III and LTE studies (crude IR (95\% CI) of 0.46 ( 0.36 to 0.59 ) per 100 patient-years); no events occurred during phase II studies and all events occurred in tofacitinib-treated patients. Crude IRs for TB and non-TB OIs were 0.21 (95\% CI 0.14 to 0.30 ) and 0.25 (95\% CI 0.18 to 0.36$)$, respectively. OIs included TB $(\mathrm{n}=26)$, oesophageal candidiasis $(\mathrm{n}=9)$, Pneumocystis jirovecii pneumonia $(n=4)$, CMV infection $(n=6)$, NTM pulmonary infection $(n=2)$, cryptococcal infection (pneumonia $n=2$, meningitis $n=1$ ), disseminated or multidermatomal herpes zoster $(n=8)$, BK encephalopathy $(n=1)$ and toxoplasmosis $(n=1)$. No cases of disseminated herpes virus or PML were reported. Of the 58 patients with OIs, one patient died due to pneumocystis, and most $(n=40)$ permanently discontinued treatment with the study drug. The CMV cases presented differently: antigenemia without evidence of other infection $(\mathrm{n}=1)$; an oesophageal ulcer, which resolved without antiviral therapy while tofacitinib treatment was continued $(n=1)$; sialadenitis with CMV on biopsy $(n=1)$; hepatitis in which CMV was also detected in cerebrospinal fluid (CSF) by PCR $(n=1)$; and gastritis with little clinical information provided $(n=1)$. The final case involved CMV retinitis with characteristic retinal pathology and a positive anterior chamber PCR; the infection responded appropriately to antiviral therapy. The case of BK encephalitis was diagnosed using PCR of CSF in a patient during an episode of bacterial sepsis; it resolved as the patient's overall status improved.

\section{All Ols (TB and non-TB Ols combined)}

In phase III studies, crude OI incidence was numerically higher in patients treated with tofacitinib $10 \mathrm{mg}$ twice daily $(0.93$ (95\% CI 0.55 to 1.58$)$ ) vs $5 \mathrm{mg}$ twice daily $(0.20$ (95\% CI 0.07 to $0.64)$ ). In LTE studies, rates were more similar in tofacitinib $5 \mathrm{mg}(0.38$ (95\% CI 0.23 to 0.62$))$ and $10 \mathrm{mg}$ treated patients (0.48 (95\% CI 0.33 to 0.71$)$ ). Across treatment arms, the crude incidence of all OIs among all tofacitinib users was slightly higher among glucocorticoid users $(0.55$ (95\% CI 0.38 to $0.81)$ ) than non-users (0.31 (95\% CI 0.19 to 0.53$))$. Rates were similar in those aged $\geq 65$ and $<65$ years $(0.49$ (95\% CI 0.24 to 1.04 ) vs 0.43 (95\% CI 0.30 to 0.60$)$ ), respectively.

\section{Ols other than TB}

Non-TB OIs occurred at a median of 40 weeks (range, 6179 weeks) after tofacitinib start. In phase III studies, the incidence of non-TB OIs was numerically higher in patients treated with tofacitinib $10 \mathrm{mg}$ twice daily $(0.40$ (95\% CI 0.18 to 0.90$)$ compared with $5 \mathrm{mg}$ twice daily (0.21 (95\% CI 0.07 to 0.64$)$ ). In LTE studies, rates were similar in tofacitinib $5 \mathrm{mg}(0.23(95 \%$ CI 0.12 to 0.43$)$ ) and $10 \mathrm{mg}$ treated patients $(0.27$ (95\% CI 0.16 to 0.46$)$ ). Across treatment arms, the crude incidence of non-TB OIs among all tofacitinib users was higher among glucocorticoid users $(0.36$ (95\% CI 0.22 to 0.58$)$ ) than non-users (0.13 (95\% CI 0.06 to 0.30$)$ ). Rates were similar in those aged $\geq 65$ and $<65$ years $(0.21$ (95\% CI 0.07 to 0.66$)$ vs $0.26(95 \%$ CI 0.17 to 0.40$)$ ).

\section{Tuberculosis}

There were 26 cases of active TB reported by investigators, all within tofacitinib-treated individuals from phase III ( $n=9$ cases) and LTE studies ( $\mathrm{n}=17$ cases). The median time between tofacitinib start and TB diagnosis was 64 weeks (range, 15-161 weeks). Fifteen $(58 \%)$ cases involved extrapulmonary infection sites. Few were culture-confirmed, and most $(20 / 26,77 \%)$ occurred in those taking tofacitinib $10 \mathrm{mg}$ twice daily (table 2). All but two cases had negative screening results at entry. The two cases with positive screening results at baseline had a history of receiving an adequate course of therapy for active TB or LTBI in the past (one each). These patients, given the adequate treatment history, were allowed into the trial without isoniazid treatment, per protocol. The TB rate varied according to regional background IR: 21 cases $(81 \%)$ occurred in countries with high background TB IR (characteristics of the 26 reported active TB cases from phase II, III and LTE studies of tofacitinib are presented in online supplementary file 3 ).

In phase III studies, crude IR of TB among all tofacitinib users was 0.27 (95\% CI 0.14 to 0.54$)$ and all cases occurred in 
Table 1 Baseline characteristics of patients entering phase III tofacitinib trials by exposure group

\begin{tabular}{|c|c|c|c|c|}
\hline $\begin{array}{l}\text { Tofacitinib } \\
5 \mathrm{mg} \text { twice daily } \\
\text { (N=1587; PY=1464.18) }\end{array}$ & $\begin{array}{l}\text { Tofacitinib } \\
10 \mathrm{mg} \text { twice daily } \\
\text { (N=1609; } \mathrm{PY}=1501.03)\end{array}$ & $\begin{array}{l}\text { Placebo } \\
\text { (N=681; PY=202.71) }\end{array}$ & $\begin{array}{l}\text { Adalimumab } \\
(\mathrm{N}=204 ; \mathrm{PY}=178.04)\end{array}$ & $\begin{array}{l}\text { Methotrexate } \\
(N=186 ; P Y=152.07)\end{array}$ \\
\hline $54(18-86)$ & $54(18-86)$ & $54(18-82)$ & $54(24-78)$ & $50.5(20-80)$ \\
\hline $1310(82.5)$ & 1355 (84.2) & $553(81.2)$ & $162(79.4)$ & $145(78.0)$ \\
\hline $976(61.5)$ & $1006(62.5)$ & 439 (64.5) & $148(72.5)$ & $127(68.3)$ \\
\hline $58(3.7)$ & $47(2.9)$ & $24(3.5)$ & $3(1.5)$ & $4(2.2)$ \\
\hline $394(24.8)$ & $375(23.3)$ & $166(24.4)$ & $29(14.2)$ & $33(17.7)$ \\
\hline $159(10)$ & $181(11.2)$ & $52(7.6)$ & $24(11.8)$ & $22(11.8)$ \\
\hline 7.4 & 7.7 & 9.3 & 8.1 & 2.6 \\
\hline $130(8.2)$ & $127(7.9)$ & $48(7.0)$ & $16(7.8)$ & $8(4.3)$ \\
\hline $125(7.9)$ & $134(8.3)$ & $64(9.4)$ & $11(5.4)$ & $9(4.8)$ \\
\hline $534(33.7)$ & $520(32.3)$ & 254 (37.4) & $71(35.1)$ & $61(32.8)$ \\
\hline $26.9(14.3-70.8)$ & $27.0(12.1-63.3)$ & $27.2(14.7-55.1)$ & $27.1(13.9-45.7)$ & $26.7(14.9-49.4)$ \\
\hline 5.4 & 5.4 & 5.3 & 5.3 & 5.6 \\
\hline $904(57.0)$ & $902(56.1)$ & $520(76.4)$ & $199(97.5)$ & $1(0.5)$ \\
\hline $91(5.7)$ & $84(5.2)$ & $34(5.0)$ & $0(0)$ & $0(0)$ \\
\hline $152(9.6)$ & $157(9.8)$ & $51(7.5)$ & $2(<1.0)$ & $26(14.0)$ \\
\hline $866(54.6)$ & $834(51.8)$ & $376(55.2)$ & $116(56.9)$ & $79(42.5)$ \\
\hline $114(7.2)$ & $113(7.0)$ & $48(7.0)$ & $16(7.8)$ & $10(5.4)$ \\
\hline 731 (46.1) & $698(43.4)$ & $315(46.3)$ & $90(44.1)$ & 68 (36.6) \\
\hline $9(<1.0)$ & $9(<1.0)$ & $5(<1.0)$ & $7(3.4)$ & $0(0)$ \\
\hline $24(1.5)$ & $20(1.2)$ & $19(2.8)$ & $3(1.5)$ & $3(1.6)$ \\
\hline
\end{tabular}

BMI, body mass index; COPD, chronic obstructive pulmonary disease; DAS28-3 CRP, Disease Activity Score using 28-joint counts and the C reactive protein level; DMARD,

disease-modifying antirheumatic drugs; PY, person-years exposure; RA, rheumatoid arthritis.

the $10 \mathrm{mg}$ twice daily group (crude incidence, $0.53(95 \% \mathrm{CI}$ 0.27 to 1.07$)$ ). IRs were similar between those aged $<65$ years $(0.54$ (95\% CI 0.26 to 1.13$))$ and those $\geq 65$ years $(0.51$ (95\% CI 0.07 to 3.63$)$ ), among those with and without baseline glucocorticoid use $(0.50$ (95\% CI 0.19 to 1.33$)$ vs 0.57 (95\% CI 0.22 to 1.53$)$ ), but trended higher in males $(1.26$ (95\% CI 0.41 to 3.90$)$ ) vs females $(0.40$ (95\% CI 0.17 to 0.95$)$ ). Within LTE studies, cases occurred at similar incidence in both 5 and $10 \mathrm{mg}$ twice daily arms (0.15 (95\% CI 0.07 to 0.33$)$ vs 0.21

Table 2 TB IRs for tofacitinib patients by background country IRs* (phase II, III and LTE studies)

\begin{tabular}{|c|c|c|c|}
\hline & $\begin{array}{l}\text { TB cases with } \\
\text { tofacitinib (n) }\end{array}$ & $\begin{array}{l}\text { Tofacitinib exposure } \\
\text { (patient-years) }\end{array}$ & $\begin{array}{l}\text { Crude TB IR } † \\
(95 \% \mathrm{Cl})\end{array}$ \\
\hline Low $¥(0.01)$ & 1 & 4852.3 & $0.02(0.003$ to 0.15$)$ \\
\hline $\begin{array}{l}\text { Medium } \S \\
(\geq 0.01 \text { and } \\
\leq 0.05)\end{array}$ & 4 & 5020.5 & $0.08(0.03$ to 0.21$)$ \\
\hline Highף $(>0.05)$ & 21 & 2791.1 & $0.75(0.49$ to 1.15$)$ \\
\hline
\end{tabular}

${ }^{*}$ TB background country IR categories from WHO, 2011 report for year $2010 .{ }^{26}$ tCrude incidence calculated TB cases per 100 patient-years.

fLow TB incidence region (total study enrolment, $n=2213)$; the USA $(n=1098)$, Czech Republic $(n=378)$, Germany $(n=238)$, Slovakia $(n=126)$, Australia $(n=114)$, Canada $(n=103)$, Austria $(n=36)$, Italy $(n=28)$, Sweden $(n=17)$, Finland $(n=16)$, Greece $(n=15)$, Belgium $(n=13)$, France $(n=10)$, Denmark $(n=9)$, New Zealand $(n=9)$ Ireland $(n=3)$. $\S$ Medium TB incidence region (total study enrolment, $n=2132)$; Japan $(n=556)$, Brazil $(n=306)$, Mexico $(n=259)$, Poland $(n=254)$, Chile $(n=174)$, Bulgaria $(n=169)$, Spain $(n=128)$, Colombia $(n=120)$, Argentina $(n=61)$, Croatia $(n=27)$, Hungary $(n=27)$, the UK $(n=17)$, Costa Rica $(n=16)$, Venezuela $(n=7)$, Bosnia-Herzegovina $(n=6)$, Turkey $(n=5)$. IHigh TB IR (total study enrolment, $n=1326)$; Korea $(n=284)$, Ukraine $(n=227)$, China $(n=213)$, India $(n=194)$, Russia $(n=149)$, Thailand $(n=63)$, Philippines $(n=61)$, Malaysia $(n=46)$, Taiwan $(n=36)$, Dominican-Republic $(n=27)$, Peru $(n=14)$, Romania $(n=12)$. $\mathrm{IR}$, incidence rate; LTE, long-term extension; TB, tuberculosis.
(95\% CI 0.12 to 0.38$)$ ). When examining IRs across dosage arms within the LTE experience, we observed higher incidence in patients aged $\geq 65$ years $(0.28$ (95\% CI 0.11 to 0.75$))$ compared with those $<65$ years $(0.17$ (95\% CI 0.10 to 0.29$))$. Rates were similar among patients using glucocorticoids $(0.19(95 \%$ CI 0.10 to 0.37$))$ and those not using glucocorticoids $(0.18$ (95\% CI 0.09 to 0.36$)$ ).

\section{TB screening results}

In phase II studies, patients screening positive for TB were disallowed entry to the trial. In phase III studies, 4088 underwent QFT-IT, of whom 217 (5.3\%) had positive results. In total, 305 patients underwent TST testing, of whom 28 (9.2\%) had positive results. Some patients lacked screening results. Presumably these patients had a history of TB (treated or untreated) elicited by site investigators; however, this information was not reliably recorded by investigators. In total, 286 patients were reported to have untreated LTBI upon screening. All of these patients completed 1 month of isoniazid prior to starting study drug or placebo, and all completed 9-month regimens of isoniazid; none developed active TB. While tofacitinib-treated patients using isoniazid were slightly more likely to develop small elevations in liver enzymes during therapy, they were no more likely to develop significant liver transaminases elevation $(>3 \times$ upper limit of normal) during therapy than tofacitinib-treated patients not using isoniazid (table 3).

\section{DISCUSSION}

We have conducted the largest analyses to date examining the risk of OIs in the context of JAK inhibition by tofacitinib. Within the global RA clinical development programme, TB was 
the most commonly reported OI but was rare in regions of low and medium background TB prevalence. In phase III trials, the incidence of OIs was higher in patients using tofacitinib $10 \mathrm{mg}$ twice daily dosing compared with tofacitinib $5 \mathrm{mg}$ twice daily dosing, and overall most TB cases occurred in patients using the higher dose. Importantly, our data suggest the utility of screening for TB prior to tofacitinib start, and the ability to successfully treat LTBI with isoniazid during tofacitinib therapy.

Patients with RA are known to be at higher risk for OIs, in part due to their therapies. For anti-TNF therapies, this increased risk has been most clearly described for those pathogens that rely upon granulomatous immunity, with $\mathrm{TB}$ the best studied example and generally the most common OI (other than routine/ uncomplicated herpes zoster) reported in that setting. ${ }^{27-30}$ Further, no matter the immunosuppressive therapy, the risk of $\mathrm{TB}$ varies directly with background $\mathrm{TB}$ rate in the underlying population, and for those starting TNF blockade, screening and treatment of LTBI effectively reduces the risk of subsequent $\mathrm{TB}^{31}$ In this regard, our experience within the tofacitinib programme was similar. TB rates among tofacitinib-treated individuals varied according to the underlying population's background TB prevalence with higher rates observed in regions of high background TB prevalence. Within North America and Western Europe, we observed TB rates 5-10 times higher than background populations and similar to those described in recent population-based studies assessing the risks of anti-TNF therapies. Early population-based studies conducted in low-prevalence $\mathrm{TB}$ regions, before widespread introduction of $\mathrm{TB}$ screening prior to biological initiation, reported rates of anti-TNF-associated TB 5-20 times higher than background general populations. ${ }^{32} 33$ The most recent observational studies conducted in the USA and Western Europe, during time periods where TB screening prior to biological start was presumably widespread, have documented similar to lower risk estimates associated with anti-TNF therapy with rates $<200$ per 100000 patient-years. ${ }^{34-36}$ This includes British and French registry studies for TB where rates were similar $(0.095-0.12$, respectively). In general, it is difficult to compare rates between studies conducted in regions where the background risk of TB may vary. The comparative risk between biologics and tofacitinib, and the

\begin{tabular}{|c|c|c|c|c|}
\hline & $\begin{array}{l}>1 \times \text { ULN } \\
\mathrm{n}(\%)\end{array}$ & $\begin{array}{l}>3 \times \text { ULN } \\
\mathrm{n}(\%)\end{array}$ & $\begin{array}{l}>5 \times \text { ULN } \\
\mathrm{n}(\%)\end{array}$ & $\begin{array}{l}>10 \times \text { ULN } \\
\text { n (\%) }\end{array}$ \\
\hline $\begin{array}{l}\text { Isoniazid/tofacitinib* } \\
(\mathrm{n}=263)\end{array}$ & $58(22.1 \%)$ & $4(1.5 \%)$ & $1(0.4 \%)$ & 0 \\
\hline $\begin{array}{l}\text { No isoniazid/tofacitinib* } \\
(\mathrm{n}=3614)\end{array}$ & $550(15.2 \%)$ & $35(1.0 \%)$ & $7(0.2 \%)$ & $2(<0.1 \%)$ \\
\hline $\begin{array}{l}\text { Isoniazid/adalimumab } \\
(n=15)\end{array}$ & $3(20 \%)$ & 0 & 0 & 0 \\
\hline $\begin{array}{l}\text { No isoniazid/adalimumab } \\
(\mathrm{n}=189)\end{array}$ & $24(12.7 \%)$ & $2(1.1 \%)$ & $1(0.5 \%)$ & 0 \\
\hline $\begin{array}{l}\text { Isoniazid/methotrexate } \\
(\mathrm{n}=8)\end{array}$ & $3(37.5 \%)$ & $1(12.5 \%)$ & 0 & 0 \\
\hline $\begin{array}{l}\text { No isoniazid methotrexate } \\
(\mathrm{n}=178)\end{array}$ & $19(10.7 \%)$ & 0 & 0 & 0 \\
\hline
\end{tabular}

In phase III trials, patients diagnosed with LTBI were allowed trial entry 1 month after starting isoniazid therapy.

*Includes patients who were randomised to tofacitinib at study start and those randomised to placebo who later took tofacitinib during their isoniazid treatment course.

ALT, alanine aminotransferase; LTBI, latent tuberculosis infection; ULN, upper limit of normal. potential risk modification of steroids, is not clear and deserves further population-based study.

Screening and treatment for LTBI prior to biological therapy has been shown to effectively reduce subsequent TB rates. ${ }^{31}$ Our data also suggest a benefit of starting antimicrobial treatment in patients diagnosed with LTBI prior to tofacitinib start. All but two of the TB cases reported in this study occurred in individuals with negative screening test results at baseline. This is not dissimilar to other clinical trial experiences with anti-TNF therapy, ${ }^{37}$ and it suggests the likelihood that some patients have false-negative screening test results at baseline. False-negative TST or Interferon-Gamma Release Assay results are more common in immunosuppressed and older patients, ${ }^{38}$ and it is possible that a strategy that uses both tests, rather than a single test as reported herein, could improve the sensitivity (and potentially decrease the specificity) of screening prior to starting biologics or tofacitinib. ${ }^{39}$ It is also possible that some of the observed TB cases were instances of newly acquired infection during the trial, given that nearly all the cases occurred in regions of high $\mathrm{TB}$ endemicity where exposure would be more likely. The long time between tofacitinib start and TB diagnosis for most of the observed cases, and their negative baseline screening results, lends further support to this idea. ${ }^{40}$ Lastly, it is possible that some of the TB cases were not true cases. We attempted to use US Centers for Disease Control and Prevention case criteria for TB in order to confirm them, but most case reports were lacking in follow-up information, making such adjudication impossible. Only 8 of the 26 cases had microbiological confirmation, and many of the patients were worked-up and diagnosed only by positive acid-fast bacilli smear and no culture was performed. In some of these cases, particularly the pulmonary cases, infection due to NTM was possible and also consistent with the negative screening test results for TB at baseline. There were at least two pulmonary NTM cases reported within the development programme. In regions of low TB prevalence, such as North America and Western Europe, NTM disease is more common than TB, ${ }^{34}{ }^{41}$ and in fact in our study only two cases of TB occurred in North America and Europe.

Both fungal and viral OIs were also identified in this study. While our data suggest an increased risk of such infections in patients using tofacitinib, it is unclear whether this risk is any different than that associated with biological therapy. It is difficult to compare overall rates of OIs between various studies due to heterogeneity in methods, and particularly due to differences in defining which OIs are considered 'opportunistic'. In population-based studies from France, Britain and the USA, reported rates vary between 152 and 3000 per 100000 , with the wide variance due to differences in case-finding methodology and OI definitions (specifically some studies included herpes zoster as an OI and others did not). ${ }^{27-30}{ }^{42-47}$ We have included only complicated cases of herpes zoster within this current analysis and have recently reported uncomplicated herpes zoster rates associated with the development programme. ${ }^{48}$ In that analysis, zoster rates were observed to be elevated with tofacitinib and to vary considerably according to enrolment region, with rates in some Asian countries approximately double those seen in Western Europe or North America. Intracellular infections with Pneumocystis, Cryptococcus and CMV were also observed in the development programme. No cases of endemic mycotic infections (histoplasmosis, coccidioidomycosis and blastomycosis) were observed, but presumably few patients were enrolled within regions where these organisms are endemic. 
A biological mechanism for how tofacitinib could increase the risk of $\mathrm{TB}$ or other intracellular infections is not yet clear. It could theoretically inhibit the development and/or maintenance of pathogen-specific memory T cells by inhibiting the intracellular signalling of IL-12, interferon (IFN)- $\gamma$ and other relevant cytokines. ${ }^{49}$ An increased risk for serious TB disease has been documented with mutations affecting IL-12, IFN- $\gamma$ and STAT1 pathways. $^{50}$ Therefore, it is possible that down-modulation of these pathways by JAK inhibition could diminish the ability of macrophages to contain infections such as TB. ${ }^{51}$ Further, it is likely that JAK inhibition diminishes type 1 (IFN- $\alpha$ and IFN- $\beta$ ) and type 2 (IFN- $\gamma$ ) antiviral responses, ${ }^{52}$ both of which signal via the JAK1 receptor. This could explain the spectrum of viral infections observed in the development programme, and such hypotheses deserve further testing.

Our experience suggests that patients can use isoniazid therapy during tofacitinib therapy with good tolerance and apparent efficacy in TB prevention. None of the $>200$ patients treated in this fashion developed clinically significant hepatitis, all completed isoniazid therapy and none developed active TB. Importantly, it should be noted that a drug-drug interaction exists between rifampin and tofacitinib such that tofacitinib could be less effective during rifampin therapy due to an $80 \%$ reduction in bioavailability of tofacitinib. ${ }^{10}$ For this reason, isoniazid should remain the drug of choice when treating LTBI during tofacitinib therapy, and periodic liver function testing should be conducted during such therapy in accordance with Centers for Disease Control and Prevention guidance. ${ }^{53}$

In summary, we observed an increased risk of OIs among patients with RA using tofacitinib, although they occur rarely and are less frequent in those treated with $5 \mathrm{mg}$ twice daily. TB was the most common OI reported in this setting, but remained rare in regions of low TB prevalence. As with biological therapy, screening and treating for LTBI should be employed prior to starting tofacitinib, and long-term population-based studies are necessary to better understand the comparative risk of tofacitinib with other DMARD therapies.

\author{
Author affiliations \\ ${ }^{1}$ Oregon Health and Science University, Portland, Oregon, USA \\ ${ }^{2}$ Division of Rheumatology, Department of Internal Medicine, Seoul St. Mary's \\ Hospital, The Catholic University of Korea, Seoul, South Korea \\ ${ }^{3}$ Istanbul Faculty of Medicine, Istanbul University, Istanbul, Turkey \\ ${ }^{4}$ Centro de Investigación Clínica de Morelia SC, Morelia, Mexico \\ ${ }^{5}$ Hospital Clínico Universitario de Santiago, Santiago de Compostela, Spain \\ ${ }^{6}$ University of Occupational and Environmental Health, Kitakyushu, Japan \\ ${ }^{7}$ Pfizer Inc, New York, New York, USA \\ ${ }^{8}$ Pfizer Inc, Collegeville, Pennsylvania, USA \\ ${ }^{9}$ Pfizer Inc, Lima, Peru \\ ${ }^{10}$ Pfizer Inc, Groton, Connecticut, USA
}

Correction notice This paper has been amended since it was published Online First. There was an error in table 2, the "Low $(<0.10)$ " has been corrected to "Low $(0.01)$ ".

\section{Twitter Follow Mario Cardiel at @mhcardiel}

Acknowledgements We wish to thank Jennifer Ku at Oregon Health \& Science University and Jason Gardner from Complete Medical Communications for assistance in formatting the manuscript. We also wish to thank Bob Burnside and Robert Chew for their statistical support and Thomas Kawabata for his input into the interpretation of the data.

Contributors For each study, adverse event data were reported by site investigators and entered within the Pfizer clinical database. Standard MedDRA codes were used to categorise adverse events. For the retrospective analysis reported herein, the analysis plan was conceived by the primary author in conjunction with collaborating authors, with statistical analysis conducted using a Pfizer statistician (RC).

Funding Pfizer Inc.

Competing interests KLW reported consulting for Genentech, Pfizer Inc, UCB and AbbVie, and research grant support from Pfizer Inc. AG reported consulting for
Pfizer Inc, MSD, AbbVie, UCB, Servier, Xoma, Novartis, Bristol-Myers Squibb and Roche. MHC has received research grants, consulting fees and/or speaking fees from Pfizer Inc, Roche, Bristol-Myers Squibb, Merck, Sanofi, Janssen, Anthera, Astellas, AbbVie, UCB and Amgen. JJG-R reported consulting for Pfizer Inc and research grant support from AbbVie, MSD, Pfizer Inc, Roche and UCB. YT has received consulting fees, speaking fees and/or honoraria from AbbVie, Chugai, Astellas, Takeda, Santen, Mitsubishi-Tanabe, Pfizer Inc, Janssen, Eisai, Daiichi-Sankyo, UCB, GlaxoSmithKline and Bristol-Myers Squibb, and has received research grants from Mitsubishi-Tanabe, Chugai, MSD, Astellas and Novartis. KK, TL, EM, DPdL, RR and HV are employees of Pfizer Inc. The contributions of JG, BB and RC were supported by Pfizer Inc.

\section{Patient consent Obtained.}

Ethics approval All clinical studies were conducted in compliance with the Helsinki declaration of Good Clinical Practice guidelines of the International Conference on Harmonisation, and all participating institutions provided ethics board approval.

Provenance and peer review Not commissioned; externally peer reviewed.

Open Access This is an Open Access article distributed in accordance with the terms of the Creative Commons Attribution (CC BY 4.0) license, which permits others to distribute, remix, adapt and build upon this work, for commercial use, provided the original work is properly cited. See: http://creativecommons.org/ licenses/by/4.0/

\section{REFERENCES}

1 Novosad SA, Winthrop KL. Beyond tumor necrosis factor inhibition: the expanding pipeline of biologic therapies for inflammatory diseases and their associated infectious sequelae. Clin Infect Dis 2014;58:1587-98.

2 Ramiro S, Gaujoux-Viala C, Nam JL, et al. Safety of synthetic and biological DMARDs: a systematic literature review informing the 2013 update of the EULAR recommendations for management of rheumatoid arthritis. Ann Rheum Dis 2014:73:529-35.

3 Jick SS, Lieberman ES, Rahman MU, et al. Glucocorticoid use, other associated factors, and the risk of tuberculosis. Arthritis Rheum 2006;55:19-26.

4 Winthrop KL, Iseman M. Bedfellows: mycobacteria and rheumatoid arthritis in the era of biologic therapy. Nat Rev Rheumatol 2013;9:524-31.

5 Deepe GS Jr. Modulation of infection with Histoplasma capsulatum by inhibition of tumor necrosis factor-alpha activity. Clin Infect Dis 2005;41(Suppl 3):S204-7.

6 Wallis RS, Broder M, Wong J, et al. Granulomatous infections due to tumor necrosis factor blockade: correction. Clin Infect Dis 2004;39:1254-5.

7 Wallis RS, Broder MS, Wong JY, et al. Granulomatous infectious diseases associated with tumor necrosis factor antagonists. Clin Infect Dis 2004;38:1261-5.

8 Marino S, Sud D, Plessner $\mathrm{H}$, et al. Differences in reactivation of tuberculosis induced from anti-TNF treatments are based on bioavailability in granulomatous tissue. PLoS Comput Biol 2007;3:1909-24.

9 Winthrop KL, Chiller T. Preventing and treating biologic-associated opportunistic infections. Nat Rev Rheumatol 2009:5:405-10.

10 Pfizer Inc. Xeljanz prescribing information. http://labeling.pfizer.com/ShowLabeling aspx?id=959 (accessed 22 Jul 2014).

11 Meyer DM, Jesson MI, Li X, et al. Anti-inflammatory activity and neutrophil reductions mediated by the JAK1/JAK3 inhibitor, CP-690,550, in rat adjuvant-induced arthritis. J Inflamm (Lond) 2010;7:41.

12 Kremer JM, Cohen $\mathrm{S}$, Wilkinson $\mathrm{BE}$, et al. A phase Ilb dose-ranging study of the oral JAK inhibitor tofacitinib (CP-690,550) versus placebo in combination with background methotrexate in patients with active rheumatoid arthritis and an inadequate response to methotrexate alone. Arthritis Rheum 2012;64:970-81.

13 Kremer JM, Bloom BJ, Breedveld FC, et al. The safety and efficacy of a JAK inhibitor in patients with active rheumatoid arthritis: Results of a double-blind, placebo-controlled phase Ila trial of three dosage levels of CP-690,550 versus placebo. Arthritis Rheum 2009;60:1895-905

14 Fleischmann $\mathrm{R}$, Cutolo $\mathrm{M}$, Genovese $\mathrm{MC}$, et al. Phase Ilb dose-ranging study of the oral JAK inhibitor tofacitinib (CP-690,550) or adalimumab monotherapy versus placebo in patients with active rheumatoid arthritis with an inadequate response to disease-modifying antirheumatic drugs. Arthritis Rheum 2012;64:617-29.

15 Tanaka Y, Suzuki M, Nakamura H, et al. Phase II study of tofacitinib $($ CP-690,550) combined with methotrexate in patients with rheumatoid arthritis and an inadequate response to methotrexate. Arthritis Care Res (Hoboken) 2011:63:1150-8

16 Tanaka Y, Takeuchi T, Yamanaka H, et al. Efficacy and safety of tofacitinib as monotherapy in Japanese patients with active rheumatoid arthritis: a 12-week, randomized, phase 2 study. Mod Rheumatol 2015;25:514-21.

17 McInnes IB, Kim HY, Lee SH, et al. Open-label tofacitinib and double-blind atorvastatin in rheumatoid arthritis patients: a randomised study. Ann Rheum Dis 2014;73:124-31

18 Burmester GR, Panaccione R, Gordon KB, et al. Adalimumab: long-term safety in 23458 patients from global clinical trials in rheumatoid arthritis, juvenile idiopathic arthritis, ankylosing spondylitis, psoriatic arthritis, psoriasis and Crohn's disease. Ann Rheum Dis 2013;72:517-24. 
19 Kremer J, Li ZG, Hall S, et al. Tofacitinib in Combination with Nonbiologic DMARDs in Patients with Active Rheumatoid Arthritis: A Randomized Trial. Ann Intern Med 2013;159:253-61.

20 Fleischmann R, Kremer J, Cush J, et al. Placebo-controlled trial of tofacitinib monotherapy in rheumatoid arthritis. N Engl J Med 2012;367:495-507.

21 van der Heijde D, Tanaka Y, Fleischmann R, et al. Tofacitinib (CP-690,550) in patients with rheumatoid arthritis receiving methotrexate: twelve-month data from a twenty-four-month phase III randomized radiographic study. Arthritis Rheum 2013;65:559-70

22 van Vollenhoven RF, Fleischmann $\mathrm{R}$, Cohen $\mathrm{S}$, et al. Tofacitinib or adalimumab versus placebo in rheumatoid arthritis. N Engl J Med 2012;367:508-19.

23 Lee EB, Fleischmann R, Hall $S$, et al. Tofacitinib versus Methotrexate in Rheumatoid Arthritis. N Engl J Med 2014;370:2377-86.

24 Wollenhaupt J, Silverfield J, Lee EB, et al. Tofacitinib, an oral janus kinase inhibitor in the treatment of rheumatoid arthritis: open-label, long-term extension safety and efficacy up to 48 months [abstract]. Arthritis Rheum 2012;64(Suppl 10):S548.

25 Yamanaka H, Tanaka Y, Takeuchi T, et al. An oral janus kinase inhibitor, as monotherapy or with background methotrexate in japanese patients with rheumatoid arthritis: a phase 2/3 long-term extension study [abstract]. Arthritis Rheum 2011;63:S473.

26 World Health Organization. Global tuberculosis control: WHO report. 2011. http:// whqlibdoc.who.int/publications/2011/9789241564380_eng.pdf (accessed 17 Oct 2014).

27 Greenberg JD, Reed G, Kremer JM, et al. Association of methotrexate and tumour necrosis factor antagonists with risk of infectious outcomes including opportunistic infections in the CORRONA registry. Ann Rheum Dis 2010;69:380-6.

28 Dixon WG, Watson $\mathrm{K}$, Lunt $\mathrm{M}$, et al. Rates of serious infection, including site-specific and bacterial intracellular infection, in rheumatoid arthritis patients receiving anti-tumor necrosis factor therapy: results from the British Society for Rheumatology Biologics Register. Arthritis Rheum 2006;54:2368-76.

29 Salmon-Ceron D, Tubach F, Lortholary 0, et al. Drug-specific risk of non-tuberculosis opportunistic infections in patients receiving anti-TNF therapy reported to the 3-year prospective French RATIO registry. Ann Rheum Dis 2011;70:616-23.

30 Winthrop KL. Infections and biologic therapy in rheumatoid arthritis: our changing understanding of risk and prevention. Rheum Dis Clin North Am 2012;38:727-45.

31 Carmona L, Gomez-Reino JJ, Rodriguez-Valverde V, et al. Effectiveness of recommendations to prevent reactivation of latent tuberculosis infection in patients treated with tumor necrosis factor antagonists. Arthritis Rheum 2005; $52: 1766-72$.

32 Askling J, Fored CM, Brandt L, et al. Risk and case characteristics of tuberculosis in rheumatoid arthritis associated with tumor necrosis factor antagonists in Sweden. Arthritis Rheum 2005;52:1986-92.

33 Wolfe F, Michaud K, Anderson J, et al. Tuberculosis infection in patients with rheumatoid arthritis and the effect of infliximab therapy. Arthritis Rheum 2004;50:372-9.

34 Winthrop K, Baxter R, Liu L, et al. Mycobacterial diseases and antitumour necrosis factor therapy in USA. Ann Rheum Dis 2013;72:37-42.

35 Arkema EV, Jonsson J, Baecklund E, et al. Are patients with rheumatoid arthritis still at an increased risk of tuberculosis and what is the role of biological treatments? Ann Rheum Dis 2015;74:1212-17.

36 Tubach F, Salmon D, Ravaud $P$, et al. Risk of tuberculosis is higher with anti-tumor necrosis factor monoclonal antibody therapy than with soluble tumor necrosis factor receptor therapy: the three-year prospective French Research Axed on Tolerance of Biotherapies registry. Arthritis Rheum 2009;60:1884-94.

37 Hsia EC, Cush JJ, Matteson EL, et al. Comprehensive tuberculosis screening program in patients with inflammatory arthritides treated with golimumab, a human anti-tumor necrosis factor antibody, in Phase III clinical trials. Arthritis Care Res (Hoboken) 2013;65:309-13.

38 Acevedo-Vasquez E, Ponce de Leon D, Gamboa-Cardena R. Latent infection and tuberculosis disease in rheumatoid arthritis patients. Rheum Dis Clin North Am 2009;35:163-81

39 Winthrop KL, Weinblatt ME, Daley CL. You can't always get what you want, but if you try sometimes (with two tests - TST and IGRA — for tuberculosis) you get what you need. Ann Rheum Dis 2012;71:1757-60.

40 Wallis RS. Mathematical modeling of the cause of tuberculosis during tumor necrosis factor blockade. Arthritis Rheum 2008;58:947-52.

41 Winthrop KL, Yamashita S, Beekmann SE, et al. Mycobacterial and other serious infections in patients receiving anti-tumor necrosis factor and other newly approved biologic therapies: case finding through the Emerging Infections Network. Clin Infect Dis 2008;46:1738-40.

42 Dixon WG, Hyrich KL, Watson KD, et al. Drug-specific risk of tuberculosis in patients with rheumatoid arthritis treated with anti-TNF therapy: results from the British Society for Rheumatology Biologics Register (BSRBR). Ann Rheum Dis 2010;69:522-8

43 Winthrop KL, Baxter R, Liu L, et al. The reliability of diagnostic coding and laboratory data to identify tuberculosis and nontuberculous mycobacterial disease among rheumatoid arthritis patients using anti-tumor necrosis factor therapy. Pharmacoepidemiol Drug Saf 2011;20:229-35.

44 Winthrop KL, Calabrese LH. Let the fog be lifted: screening for hepatitis B virus before biological therapy. Ann Rheum Dis 2011;70:1701-3.

45 McDonald JR, Zeringue AL, Caplan L, et al. Herpes zoster risk factors in a national cohort of veterans with rheumatoid arthritis. Clin Infect Dis 2009;48:1364-71.

46 Strangfeld A, Eveslage M, Schneider M, et al. Treatment benefit or survival of the fittest: what drives the time-dependent decrease in serious infection rates under TNF inhibition and what does this imply for the individual patient? Ann Rheum Dis 2011;70:1914-20.

47 Galloway JB, Hyrich KL, Mercer LK, et al. Risk of septic arthritis in patients with rheumatoid arthritis and the effect of anti-TNF therapy: results from the British Society for Rheumatology Biologics Register. Ann Rheum Dis 2011;70:1810-14.

48 Winthrop KL, Yamanaka H, Valdez H, et al. Herpes zoster and tofacitinib therapy in patients with rheumatoid arthritis. Arthritis Rheumatol 2014;66:2675-84.

49 Paniagua R, Si MS, Flores MG, et al. Effects of JAK3 inhibition with CP-690,550 on immune cell populations and their functions in nonhuman primate recipients of kidney allografts. Transplantation 2005;80:1283-92.

50 Abel L, El-Baghdadi J, Bousfiha AA, et al. Human genetics of tuberculosis: a long and winding road. Philos Trans R Soc Lond B Biol Sci 2014;369:20130428.

51 Maiga M, Lun $S$, Guo $H$, et al. Risk of tuberculosis reactivation with tofacitinib (CP-690550). J Infect Dis 2012;205:1705-8.

52 Malmgaard L. Induction and regulation of IFNs during viral infections. J Interferon Cytokine Res 2004;24:439-54.

53 American Thoracic Society, Centers for Disease Control and Prevention. Targeted tuberculin testing and treatment of latent tuberculosis infection. MMWR 2000;49(RR06):1-54. 